\title{
EDUCAÇÃO ESPECIAL NA PERSPECTIVA DA EDUCAÇÃO INCLUSIVA EM UM MUNICÍPIO DE MATO GROSSO DO SUL
}

\author{
Mônica de Carvalho Magalhães Kassar'Đ \\ Andressa Santos Rebelo ${ }^{1}$ (1) \\ Marcelo Messias Rondon ${ }^{1}$ \\ José Fonseca da Rocha Filho ${ }^{1}$
}

\begin{abstract}
RESUMO: Este texto propóe-se a analisar a implantação da política de educaçáo especial na perspectiva da educação inclusiva em um município do interior do estado de Mato Grosso do Sul. Foram consultados documentos, dados oficiais da educação brasileira e pesquisas que trataram sobre a educação especial na região. As análises evidenciam, por um lado, a consolidação da rede municipal de educação e o fortalecimento da educação especial, especialmente após 2004, e por outro, os limites no atendimento oferecido aos alunos da educação especial próximos aos do atendimento oferecido à educação em geral.
\end{abstract}

Palavras-chave: Educação especial. Educação inclusiva. Política de inclusão escolar.

\section{Special education in the inclusive education perspective in a municipality of Mato Grosso do Sul, Brazil}

ABSTRACT: This article seeks to investigate the implantation of special education in an inclusive perspective, in a municipality in the State of Mato Grosso do Sul. Documents, Brazilian education official data and researches that address special education in this region were consulted. The analyses show, at

\footnotetext{
${ }^{1}$ Universidade Federal de Mato Grosso do Sul - Campo Grande (MS), Brasil.

E-mails: monica.kassar@gmail.com; andressarbl@gmail.com; marcellomrondon@hotmail.com; jotafon@gmail.com

DOI: 10.1590/CC0101-32622018199077
} 
one hand, the entrenchment of the municipal system and the empowerment of special education, mainly after 2004, and at another, the limits of the care provided to special students as close as the limits of the care provided in general.

Keywords: Special education. Inclusive education. Educational inclusive policy.

\section{INTRODUÇÃO}

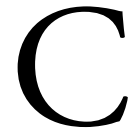

om a Constituição Federal de 1988 e, especificamente, a aprovação da Emenda Constitucional no 14, de 1996, a organizaçáo da política educacional brasileira, normatizada pela Lei de Diretrizes e Bases (Lei 9.394/96), passa a obedecer a uma ordem em que parte de suas açóes é gerida pelo poder local/municipal. Nessa estrutura, os municípios devem organizar seus sistemas de ensino e atuar prioritariamente no ensino fundamental e na educação infantil (art. 2o). Vieira et al. (2013, p. 10) entendem que o conceito de poder local, sob uma perspectiva progressista, apresentaria um potencial "de intervenção positiva dos principais interessados nos destinos da vida pública”, mas, também, o conceito é associado historicamente a "atraso político e práticas conservadoras, por excelência, que inibem o avanço desta mesma vida pública” (VIEIRA et al., 2013, p. 11). Considerando possíveis paradoxos existentes na ação do poder local, o fato é que sob essa esfera, projetos e programas são implementados e tal implementação sempre envolve decisóes.

A política educacional do período pós-constitucional também é marcada por um esforço conjugado para cumprir o compromisso de universalização da escolaridade obrigatória (BRASIL, 1993) e incorpora e dissemina o discurso de educaçáo inclusiva. A partir de 2003, o governo federal alinhou nitidamente suas açóes e programas a essa perspectiva e instituiu o programa "Educação inclusiva: o direito à diversidade", com o objetivo de transformar os sistemas escolares em um sistema educacional inclusivo (BRASIL, 2004). O documento "Política Nacional de Educação Especial na Perspectiva da Educação Inclusiva”, 
de 2008 (BRASIL, 2008), é divulgado e ratifica esse objetivo ao orientar as açóes para os alunos da educação especial $(\mathrm{EE})^{1}$.

As políticas de inclusão estão presentes em diferentes países e encontram eco e suporte em diretrizes de organismos multilaterais (UNESCO, 1994). Mas, mesmo elaboradas sob as influências globais, as políticas com seus conceitos e programas recebem leituras e procedimentos peculiares, quando apropriadas em cada regiâo (CAIADO \& LAPLANE, 2009).

Com a intenção de avançar no conhecimento a respeito da implantação da política de educação inclusiva na esfera local, este texto propóe-se a analisar suas especificidades em um município do interior do estado de Mato Grosso do Sul. A escolha dessa regiáo justifica-se por: tratar-se de um município polo ${ }^{2}$ na implantação de programas de educação inclusiva do governo federal; ser uma região relativamente isolada em relação a outros núcleos populacionais, o que pode induzir a certa "autossuficiência" de açóes; e pelo fato de o município já possuir história de educação especial por açóes do governo do estado anteriores à implantação das ações iniciadas em 2003. Para seu desenvolvimento foram consultados documentos das esferas federal, estadual e municipal, microdados do Censo Escolar da Educação Básica e trabalhos de pesquisa que tratam da $\mathrm{EE}$ na região. As análises foram construídas a partir de elementos qualitativos e quantitativos (GAMBOA, 1994), sob a perspectiva de que o nexo quantidade-qualidade é indissociável, já que o movimento histórico envolve alteraçóes dos dois âmbitos (GRAMSCI, 1987; FERRARO, 2012).

O município em foco, Corumbá, é um dos mais antigos povoamentos do estado, com fundação em 1778. Trata-se de um município com história significativa para a formação econômica e social do país (polo econômico e de distribuição fluvial de mercadorias entre o fim do século XIX e o início do século XX, palco da Guerra do Paraguai) em um estado recentemente criado ${ }^{3}$. Está localizado na região do Pantanal e faz fronteira com a Bolívia e o Paraguai; com o primeiro, pela localização geográfica, o trânsito de pessoas é intenso, de modo que muitas crianças desse país estudam em escolas corumbaenses. A atividade econômica baseia-se na extração mineral, pecuária e em uma atividade turística não plenamente desenvolvida (ROCHA FILHO, 2015). 
As características geográficas e históricas marcam a organização da rede municipal de educação, com escolas funcionando em prédios históricos, onde a acessibilidade arquitetônica é dificultada, e outras situadas muito distantes do polo urbano, com acesso exclusivo por navegação. O município tem, também, muitos alunos no ensino fundamental que têm o espanhol como língua materna.

Dados atuais do Instituto Brasileiro de Geografia e Estatística (IBGE, 2017) registram população de 103.703 pessoas, sendo que apenas aproximadamente $10 \%$ vivem na zona rural. Desses, grande parte está nos oito assentamentos rurais do município. Nas fazendas de criação de bovinos, a concentração populacional é baixa, pois é uma atividade econômica que não envolve grande número pessoas. $\mathrm{O}$ Censo Escolar registra 63 instituições de educação básica, com 28.453 matrículas: 1 federal, 11 estaduais, 16 privadas e 35 municipais. Destas, 24 localizam-se na zona urbana e 11 na zona rural (INEP, 2017).

O Índice de Desenvolvimento Humano Municipal (IDHM) atual está no limite inferior do que é considerado "alto" (IBGE, 2017) e o IDHM-Educação é o que mais contribui para baixar o IDHM do município, pois os indicadores educacionais são bastante desfavoráveis, com taxas de distorção idade-série e de reprovação acima dos índices estadual e federal (INEP, 2016).

\section{CORUMBÁ COMO LÓCUS DE POLÍTICAS DE EDUCAÇÃO ESPECIAL}

As primeiras ações públicas para alunos da EE em Corumbá datam do período da formação do estado, entre 1977 e 1979, posteriores à criação da única instituição especializada privado-filantrópica do município, fundada em 1971 (BRASIL, 1975). A capacitação de professores para atuar na área ocorre a partir de 1975, quando o município fazia parte de Mato Grosso (CORUMBÁ, 2008) e o Centro Nacional de Educação Especial (CENESP) impulsionou cursos em EE por todo o país (KASSAR, 1993). 
Com o novo estado, cria-se a Diretoria de Educação Especial na Secretaria de Estado de Educação. Corumbá passa a contar com sete classes especiais para "deficientes mentais educáveis" (DME) e uma para "deficientes auditivos" em escolas da rede estadual (MATO GROSSO DO SUL, 1986). A partir de 1988, os alunos de classes especiais para DME passam por um processo de avaliação diagnóstica e, como decorrência, há diminuição de alunos por sala (KASSAR, 1993). O processo de diagnóstico expôs uma situaçáo que a literatura especializada já vinha denunciando desde o final da década de 1980; as classes especiais eram compostas por alunos que "atrapalhavam” a escola (PASCHOALICK, 1981; ALMEIDA, 1984). Diante do quadro evidenciado, a Secretaria de Estado de Educação encerrou o funcionamento dessas classes e instalou salas de recursos para atendimento complementar à escolaridade recebida nas salas de aulas comuns (KASSAR, 2000).

Na década de 1990, a Secretaria de Educação Especial (SEESP/ MEC) recomenda que os municípios passem a se responsabilizar pela EE, sugerindo a criação de um setor para essa linha de ação (BRASIL, 1994). Como já registrado no início deste texto, também nessa década, alterações na Constituição Federal e a aprovação da Lei de Diretrizes e Bases, em 1996, passaram a considerar o município como ente responsável por parte significativa da escolarização obrigatória, decorrendo, daí, uma municipalização das matrículas no ensino fundamental, impulsionada, dentre outros fatores, pela criação do Fundo de Manutenção e Desenvolvimento do Ensino Fundamental (GOUVEIA, 2008). A partir de então, o município organiza-se seguindo as proposiçôes da política educacional nacional e assume seu lugar de segmento responsável por parte da escolarização obrigatória. A atenção aos alunos da EE deve ser entendida nessa configuração.

Iniciam-se, então, em Corumbá, ações para organizar seu sistema municipal de educação, com atendimento voltado ao ensino fundamental e à educação infantil e, dentre esses, a alunos da EE. Uma "Política Municipal de Educação Especial para as escolas da Rede Municipal de Ensino e Escolas de Educação Infantil da Rede Privada" foi elaborada em 2000, priorizando o atendimento na escola comum com articulação à instituição especializada local, e propôs a organização de 
um centro de EE. Parte do que foi proposto nesse documento reaparece em 2003, em uma deliberação que "estabelece a Política Municipal de Educação Especial na Educação Básica para as unidades escolares pertencentes ao sistema municipal de ensino" (CORUMBÁ, 2003). No mesmo ano, a Secretaria Municipal de Educação (SMEC) atende ao programa "Educação Inclusiva: o Direito à Diversidade" e participa de formaçôes nacionais para gestores, em Brasília (BRASIL, 2004). A partir daí, Corumbá assume um polo de formaçáo do programa, responsabilizando-se por sua rede e por 12 municípios.

Nesse contexto, as secretarias municipais de educação e de saúde implantam, em 2004, um núcleo de EE, o Centro Multiprofissional de Apoio ao Desenvolvimento Infanto-Juvenil (CMADIJ), com objetivo de dar suporte aos alunos da EE matriculados em classes comuns, com a oferta de atendimentos educacionais e da saúde (RODRIGUES, 2008). O CMADIJ encontra-se instalado em um prédio de uma escola municipal e, em sua origem, contava com profissionais da área da pedagogia — para açóes de orientação a escolas e atendimento em salas de recursos — e da área da saúde: fisioterapia, fonoaudiologia, psicologia, neurologia pediátrica e odontologia — para atendimento às crianças e orientaçóes às famílias e escolas. Antes da implantação desse setor, os alunos recorriam à instituição especializada privado-filantrópica, que funciona com auxílio financeiro público, por meio de convênios. Na sequência, uma sala de recursos multifuncionais é implantada, em 2005, antes mesmo do lançamento do programa do governo federal "Implantação de Salas de Recursos Multifuncionais". Em 2007, Corumbá recebe o Programa Escola Acessível (PEA) (SILVA FILHO, 2017).

Quando da divulgação do documento da "Política Nacional de Educação Especial na Perspectiva de Educação Inclusiva”, em 2008, o município também traça sua política, com detalhamentos para a organização das escolas, como o limite máximo de alunos por sala, e prevê a existência de salas de recursos multifuncionais, salas psicopedagógicas, intérprete da língua de sinais, instrutor de língua brasileira de sinais, transporte escolar adaptado e atendimento especializado nas áreas de educação e saúde (CORUMBÁ, 2008). Nesse ano também foi criado o Conselho Municipal de Defesa dos Direitos da Pessoa com De- 
ficiência. A parir daí, 6 escolas municipais recebem salas de recursos multifuncionais (REBELO, 2012) e 12 são contempladas com obras de acessibilidade arquitetônica, seja com recursos do PEA (9 escolas), seja com recursos próprios municipais. Dentre elas, duas estão na região rural (SILVA FILHO, 2017).

A Tabela 1 apresenta as matrículas de alunos da EE em escolas especiais e no ensino regular na educação básica em Corumbá, por dependência administrativa, em intervalos, entre 2000 a 2017.

Acredita-se que as implantaçóes do CMADIJ e da primeira sala de recursos multifuncional favoreceram o início das matrículas de alunos da EE na rede municipal, que ocorre apenas em 2004. Em 2013, essa rede passa a possuir a maior quantidade de matrículas de EE nessa localidade. Cabe esclarecer que no total de matrículas da rede privada, em 2017, há registros de oito em classes comuns (INEP, 2017).

\section{Tabela 1}

Matrículas de alunos da educação especial (escolas especiais e ensino regular) na educaçáo básica em Corumbá, Mato Grosso do Sul, por dependência administrativa, em intervalos, entre 2000 e 2017.

\begin{tabular}{l|c|c|c|c|c|c}
\hline & Federal & Estadual & Municipal & Privada & $\begin{array}{c}\text { Total de } \\
\text { alunos na } \\
\text { educaçáo } \\
\text { especial }\end{array}$ & $\begin{array}{c}\text { Matrículas } \\
\text { gerais }\end{array}$ \\
\hline 2000 & - & 30 & 0 & 107 & 137 & 31.169 \\
\hline 2004 & - & 26 & 34 & 122 & 148 & 34.533 \\
\hline 2008 & - & 64 & 68 & 147 & 279 & 34.934 \\
\hline 2012 & $0^{*}$ & 84 & 142 & 159 & 364 & 32.205 \\
\hline 2016 & 0 & 95 & 287 & 151 & 533 & $28.951^{* *}$ \\
\hline 2017 & 2 & 101 & 248 & 141 & 492 & $28.453^{* *}$ \\
\hline
\end{tabular}

Fonte: com base em INEP (2018a; 2018b).

Estão considerados: educação básica, educação profissional e educação de jovens e adultos; *Instituto Federal de Mato Grosso do Sul (IFMS) - local é implantado em 2011; ** nas bases de 2016 e 2017, não se sabe se as matrículas da educaşão especial estão incluidas no valor total. 
Dados do censo registram ainda que das 492 matrículas de alunos da EE em 2017, a maior parte está nos anos iniciais do ensino fundamental (334) e dessas, 121 estão na situação de educação substitutiva em classes exclusivas (na escola especializada). $\mathrm{O}$ número de matrículas na educação infantil é pequeno ( 2 em creches e 24 em pré-escolas), fato não exclusivo desse município, já que reflete o panorama nacional (BUENO \& MELETTI, 2011; GÓES, 2014). Kassar e Marcelo (2016) evidenciam que das poucas matrículas nessa etapa em Mato Grosso do Sul, quase a totalidade encontra-se em instituiçôes do tipo associação de pais e amigos dos excepcionais/Pestalozzi. No ensino médio, as matrículas de alunos da EE também não são significativas (18 da totalidade). Há, ainda, 30 matrículas de alunos da EE na educação de jovens e adultos e 3 em educação profissional.

Em toda a rede pública local, há 16 salas de recursos para atendimento educacional especializado, sendo 13 em escolas da zona urbana (6 em escolas estaduais e 7 em municipais ${ }^{4}$ ) e 3 em escolas rurais ( 1 em escola estadual e 2 em municipais). Tais salas parecem não ser suficientes para atender toda a populaçáo da EE, pois a porcentagem de matrículas nas salas de recursos em relação às matrículas de alunos da EE nas classes comuns, que era de 80,37\% em 2009, diminuiu para 23,98\% em 2017 (INEP, 2017). Vê-se, portanto, que o crescimento das matrículas nas salas comuns não tem sido acompanhado pelo aumento do atendimento educacional especializado.

Como registrado anteriormente, mesmo que a política implantada localmente seja segmento de políticas emanadas pela esfera central, no município desenvolve-se com características distintas (CAIADO \& LAPLANE, 2009). A comparação entre as estratégias do Plano Nacional de Educação (PNE) (2014) e do Plano Municipal de Educação (PME) (2015) indica que Corumbá procura adequar suas metas ao contexto local, referindo-se às suas características: escolas urbanas, do campo, das águas, de fronteiras, indígenas e de comunidades quilombolas. Ressalta-se, no entanto, que o município não adota a estratégia do plano nacional de "garantir a oferta de educação inclusiva, vedada a exclusão do ensino regular sob alegação de deficiência e promovida a articulação pedagógica entre o ensino regular e o atendimento educacional especializado" (BRASIL, 2014, grifo nosso) e os dados de matrículas mostram 
a constante procura pela instituição especializada. Ainda em 2015, um diagnóstico apresentado no PME registrou que o CMADIJ havia perdido seus profissionais da área da saúde, presentes à época de sua criação (CORUMBÁ, 2015).

O constante número de matrículas na instituição privada e a não adoção da estratégia do $\mathrm{PNE}$, referida anteriormente, podem ser indicativos da força da instituição privada na política local e estar relacionados à retirada dos profissionais do campo da saúde do CMADIJ, pois concomitante a essa ocorrência, a prefeitura assina um convênio entre a administração municipal e a instituição, possibilitando sua habilitação como centro especializado em reabilitação, integrando-se, assim, à Rede de Cuidados à Pessoa com Deficiência no âmbito do Sistema Único de Saúde (SUS).

A recomendação de parcerias entre os setores público e privado está presente na política nacional (BRASIL, 2008) e em documentos dos organismos internacionais (UNESCO, 1994). No entanto, nos documentos direcionadores da política de educação inclusiva, as parcerias são recomendadas de forma a complementar a escolarização em classes comuns, na formação de professores especializados ou no oferecimento de pessoal de apoio para atendimento especializado.

Importante registrar que essas parcerias, em todos os casos, ocorrem com o financiamento público das açóes privadas e desobrigam o poder público de aprimorar suas instituiçóes (PERONI, 2012; 2013).

\section{CONSIDERAÇÕES FINAIS}

A rede municipal de Corumbá ensaia a proposição de açóes aos alunos da EE desde o início da década de 2000. As matrículas aparecem a partir de 2004, com crescimento contínuo desde então. Nesse ínterim, o município organiza-se alinhado às proposiçóes do governo federal, mas com certa independência, propondo açôes não explicitamente previstas nas orientaçốes nacionais ou suprindo suas lacunas, como a criação de um órgão com a característica do CMADIJ, o estabelecimento de limite máximo de alunos por sala de aula e a realização de obras de acessibilidade com recursos próprios. 
Ao olhar esse percurso, é possível afirmar que o empenho demonstrado não tem garantido suficiência no atendimento: menos de $25 \%$ dos alunos da EE recebem atendimento educacional especializado. Além de pequena cobertura dos atendimentos especializados, a abrangência das ações no CMADIJ também recuou, já que o setor perdeu seus profissionais da área da saúde. Resta à população voltar a procurar a instituição especializada privado-filantrópica.

Estudos evidenciam que apesar de formalmente matriculados, não há garantia de que os alunos da EE estejam recebendo escolaridade adequada (FRANÇOZO, 2014; SERAFIM, 2014). Ressalta-se que os problemas educacionais não são exclusivos dos alunos da EE. O baixo IDHM-Educação local não é apenas um número em um relatório, mas é indicativo de problemas educacionais, não apenas exibidos em estudos quantitativos, mas também em pesquisas produzidas nas escolas.

Como registrado neste artigo, na política em implantação, instituiçõos privadas fazem parte da construção de um sistema educacional inclusivo, dentro da concepção de parcerias (UNESCO, 1994). Retomando as análises de Vieira et al. (2013) sobre possíveis características do poder local, entendemos que o encolhimento das açóes do CMADIJ é uma opção política local, que reforça o protagonismo da instituição especializada privado-filantrópica como porta-voz da EE. Implantado em 2004, a existência do CMADIJ era vista como formalização da responsabilidade pública dentro das políticas de inclusão (RODRIGUES \& KASSAR, 2009). Com mudanças na gestáo municipal, o centro foi descaracterizado e, em contrapartida, a instituição especializada privado-filantrópica integrou-se à Rede de Cuidados à Pessoa com Deficiência no âmbito do SUS. Esse movimento leva a suspeitar que exista intervenção da instituição privado-filantrópica local no direcionamento das políticas públicas em Corumbá, que desvaloriza o espaço público em detrimento da valorização do privado (sustentado com recursos públicos). Jannuzzi (1985) registra a influência dessas associaçóes nos rumos das políticas nacionais de educação especial e é possível que esse também seja o caso aqui.

Os dados desse município indicam que o que a política nacional propóe não é muito diferente da forma como a região já se organizava 
para atender os alunos da EE. No entanto, não é possível ignorar a força de indução que as açóes federais têm sobre essa localidade, cujos resultados podem ser aferidos na crescente matrícula de alunos nas escolas comuns e na ampliação das salas de recursos.

A situação descrita neste artigo indica um movimento complexo na organização e no delineamento das políticas educacionais; se há influência das políticas globais para o local (GARCIA, 2008), que repercute e direciona as ações conforme as possibilidades e relaçóes de cada regiáo, o movimento local também parece fornecer elementos para a constituição de planos e estratégias globais (CÔRTES, 2002; KOERNER, 2003).

Cabe ainda dizer que não garantir condiçóes adequadas de funcionamento dos atendimentos de educação e de saúde públicos implica a inviabilidade do exercício desses setores como direitos da população. Côrtes (2002) chama a atenção para as possibilidades de protagonismo dos conselhos das áreas sociais. Em um cenário de desafios, como o apresentado, o Conselho Municipal de Defesa dos Direitos da Pessoa com Deficiência ganha importância como pressão à responsabilização do município quanto à educação obrigatória e demais atendimentos necessários para a plena efetivação desses direitos, pois responsabilidade significa mais do que a aceitação formal de compromissos.

\section{NOTAS}

1. Utilizamos alunos da "educação especial", pois é a forma utilizada nas orientaçóes do Censo Escolar.

2. O "Programa Educação Inclusiva: o direito a diversidade" foi organizado por meio de municípios polo e municípios de abrangência. Corumbá constituiu-se município polo, com a responsabilidade de repassar as formaçôes a 12 municípios de abrangência.

3. O estado de Mato Grosso do Sul foi instalado em 1979, com sua criaçáo determinada pela Lei complementar $\mathrm{n}^{\circ}$ 31, de 11 de outubro de 1977.

4. Implantadas em seis escolas. 


\section{REFERÊNCIAS}

ALMEIDA, C.S. Análise dos motivos de encaminhamentos de alunos de classes comuns a classes especiais de escolas públicas de primeiro grau. Dissertação (Mestrado) - Universidade Federal de São Carlos, São Carlos, 1984.

BRASIL. Educação Inclusiva: o direito à diversidade. Brasília: Secretaria de Educação Especial, 2004. v. 1.

. Ministério da Educação. Centro Nacional de Educação Especial. Educação Especial: Cadastro Geral dos Estabelecimentos de Ensino Especial. Brasília: Ministério da Educação, 1975. v. 2.

Ministério da Educação. Secretaria de Educação Especial. Expansão e melhoria da educação especial nos municípios brasileiros. Brasília: Secretaria de Educação Especial, 1994.

Ministério da Educação. Secretaria de Educação Especial. Política Nacional de Educação Especial na Perspectiva da Educação Inclusiva. Brasília: Secretaria de Educação Especial, 2008.

. Plano Decenal de Educação para Todos 1993-2003. Brasília: Ministério da Educação, 1993.

. Presidência da República. Lei no 13.005, de 25 de junho de 2014. Aprova o Plano Nacional de Educação - PNE e dá outras providências. Diário Oficial da República Federativa do Brasil, Brasília, 2014.

BUENO, J.G.S.; MELETTI, S.M.F. Educaçáo infantil e educação especial: uma análise dos indicadores educacionais brasileiros. Contrapontos, v. 11, p. 278-287, n. 3, set./dez. 2011.

CAIADO, K.R.M.; LAPLANE, A.L.F. Programa Educação inclusiva: direito à diversidade: uma análise a partir da visão de gestores de um município-pólo. Educação e Pesquisa, Sáo Paulo, v. 35, n. 2, p. 303-315, maio/ago. 2009. http:// dx.doi.org/10.1590/S1517-97022009000200006

CÔRTES, S. Viabilizando a participação em conselhos de política pública municipais: arcabouço institucional, organização do movimento popular e policy communities. In: ENCONTRO ANUAL DA ANPOCS, 25., 2002. Anais... Caxambu, 2002.

CORUMBÁ. Deliberação CME/MS no 74/2003, de 27 de novembro de 2003. Estabelece a Política Municipal de Educação Especial na Educação Básica para as unidades escolares pertencentes ao sistema municipal de ensino. Corumbá, 2003. 
. Lei no 2.484, de 26 de junho de 2015, que aprova o Plano Municipal de Educação do município de Corumbá. Diário Oficial de Corumbá, Corumbá, 2015.

- Política municipal da educação especial na perspectiva da educação inclusiva. Corumbá, 2008.

FERRARO, A.R. Quantidade e qualidade na pesquisa em educação, na perspectiva da dialética marxista. Pro-Posiçôes, Campinas, v. 23, n. 1 (67), p. 129-146, jan./abr. 2012.

FRANÇOZO, R.V. O Atendimento Educacional Especializado para estudantes com deficiência visual em Corumbá-MS e Ladário-MS. Dissertação (Mestrado em Educação) - Universidade Federal do Mato Grosso do Sul, Corumbá, 2014.

GAMBOA, S.A.S. A dialética na pesquisa em educação: elementos de contexto. In: FAZENDA, I. (Org.). Metodologia da pesquisa educacional. 3. Ed. São Paulo: Cortez, 1994.

GARCIA, R.M.C. Políticas inclusivas na educação: do global ao local. In: BAPTISTA, C.R.; CAIADO, K.R.M.; JESUS, D.M. (Orgs.). Educação especial: diálogo e pluralidade. Porto Alegre: Mediação, 2008. V. 1. P. 11-23.

GÓES, R.S. Escolarização de alunos com deficiência intelectual: as estatísticas educacionais como expressão das politicas de educação especial no Brasil. 122f. Tese (Doutorado em Educação) - Pontifícia Universidade Católica de São Paulo, São Paulo, 2014.

GOUVEIA, A.B. Financiamento da educação e o município na federação brasileira. Revista Brasileira de Política e Administração da Educação, v. 24, n. 3, p. 437-465, set./dez. 2008. https://doi.org/10.21573/vol24n32008.19267

GRAMSCI, A. Concepção dialética da história. Tradução de Carlos Nelson Coutinho. 7. Ed. Rio de Janeiro: Civilização Brasileira, 1987.

INSTITUTO BRASILEIRO DE GEOGRAFIA E ESTATÍSTICA (IBGE). Corumbá: síntese das informaçôes. IBGE. Disponível em: <https://cidades.ibge. gov.br/brasil/ms/corumba >. Acesso em: 24 mar. 2017.

INSTITUTO NACIONAL DE ESTUDOS E PESQUISAS EDUCACIONAIS ANÍSIO TEIXEIRA (INEP). Censo escolar. Brasil, 2018a. Disponível em: <http://portal.inep.gov.br/web/guest/censo-escolar>. Acesso em: 14 abr. 2018.

. Censo Escolar da Educação Básica 2016. Brasília: INEP, 2016.

. Censo Escolar da Educaçâo Básica 2017. Brasília: INEP, 2017. 
. Sinopses Estatísticas da Educação Básica. Brasil, 2018b. Disponível em: $<$ http://inep.gov.br/sinopses-estatisticas-da-educacao-basica $>$. Acesso em: 14 abr. 2018.

JANNUZZI, G. A luta da educação do deficiente mental no Brasil. São Paulo: Cortez/Autores Associados, 1985.

KASSAR, M.C.M. A deficiência mental na voz das professoras. Dissertação (Mestrado em Educaçáo) - Universidade Federal de Mato Grosso do Sul, Campo Grande, 1993.

Conhecimento e análise da política de atendimento educacional ao Portador de Necessidades Especiais em Mato Grosso do Sul. In: SENNA, E. (Org.). Política Educacional de Mato Grosso do Sul na trajetória das políticas sociais. Campo Grande: Universidade Federal de Mato Grosso do Sul, 2000. P. 137-166.

KASSAR, M.C.M.; MARCELO, R.M. Atendimento educacional especializado a crianças pequenas com deficiência: o caso de Mato Grosso do Sul. Comunicaçôes, v. 23, p. $27-42$, 2016. http://dx.doi.org/10.15600/2238-121X/comunicacoes. v23nespp27-42

KOERNER, A. O papel dos direitos humanos na política democrática: uma análise preliminar. Revista Brasileira de Ciências Sociais, v. 18, n. 53, out. 2003. http://dx.doi.org/10.1590/S0102-69092003000300009

MATO GROSSO DO SUL. Secretaria de Educação. Diretoria de Educação Especial. Educação Especial em Mato Grosso do Sul: coleta 85. Campo Grande: Secretaria de Educação, 1986.

ORGANIZAÇÃO DAS NAÇÕES UNIDAS PARA A EDUCAÇÃO, A CIÊNCIA E A CULTURA (UNESCO). Declaração de Salamanca: sobre princípios, políticas e práticas na área de necessidades educativas especiais. Espanha: UNESCO, 1994.

PASCHOALICK, W. Análise do processo de encaminhamento de crianças das classes especiais para deficientes mentais, desenvolvido nas escolas de $1^{\circ} \mathrm{grau} d a$ delegacia de ensino de Marília. Dissertação (Mestrado) - Pontifícia Universidade Católica de São Paulo, São Paulo, 1981.

PERONI, V.M.V. A gestão democrática da educação em tempos de parceria entre o público e o privado. Pro-Posiçóes, Campinas, v. 23, n. 2, p. 19-31, ago. 2012. http://dx.doi.org/10.1590/S0103-73072012000200003

. As relaçôes entre o público e o privado nas políticas educacionais no contexto da terceira via. Currículo sem Fronteiras, v. 13, n. 2, p. 234-255, maio/ ago. 2013. 
REBELO, A.S. Os impactos da politica de Atendimento Educacional Especializado: análise dos indicadores educacionais de matrículas de alunos com deficiência. Dissertação (Mestrado em Educação) - Universidade Federal de Mato Grosso do Sul, Corumbá, 2012.

ROCHA FILHO, J.F. Atividades turisticas e cultura na paisagem pantaneira dos municípios de Aquidauana e Corumbá no estado de Mato Grosso do Sul - Brasil. Tese (Doutorado em Geografia Humana) - Universidade de São Paulo, São Paulo, 2015.

RODRIGUES, A.P.N. O papel do núcleo de educação especial para a implantação da educação inclusiva no município de Corumbá-MS [Relatório de PIBIC]. Corumbá: UFMS, CNPq, 2008.

RODRIGUES, A.P.N.; KASSAR, M.C.M. O núcleo de Educação Especial e a efetivação da Educação Inclusiva no município de Corumbá [Relatório de PIBIC]. Corumbá: UFMS, CNPq, 2009.

SERAFIM, F.G. Os labirintos da política de educação inclusiva: entre o preconceito $e$ o direito à educação. Dissertação (Mestrado em Educação) - Universidade Federal de Mato Grosso do Sul, Corumbá, 2014.

SILVA FILHO, D.M. Acessibilidade: uma análise da existência de barreiras à inclusão de alunos com deficiência/NEE na rede municipal de ensino de Corumbá, MS. Dissertação (Mestrado em Educação) - Universidade Federal de Mato Grosso do Sul, Corumbá, 2017.

VIEIRA, S.L.; VIDAL, E.M.; MENEGHEL, S.M.; MOREIRA, A.N.G. Política educacional e poder local em pequenos municípios. In: XXVI Simpósio Brasileiro de Política e Administração da Educação, 26., 2013. Anais... p. 1-17. Disponível em: <http://www.anpae.org.br/simposio26/1comunicacoes/ SofiaLercheVieira-ComunicacaoOral-int.pdf>. Acesso em: maio 2018.

Recebido em 15 de maio de 2018.

Aprovado em 02 de agosto de 2018.

(C) 2018 Centro de Estudos Educação e Sociedade - CEDES Este é um artigo de acesso aberto distribuído nos termos de licença Creative Commons. 